\title{
Current Situation and Educational Countermeasures on Left Behind Children in Rural
}

\author{
Nan Cui ${ }^{\mathrm{a}}$, Jun Yang ${ }^{\mathrm{b}}$ \\ School of Education and Sports, Bohai University, Jinzhou, 121013, China \\ alianjiacui@qq.com, b444530141@qq.com
}

Keywords: rural; left behind children; family education; current situation; countermeasures

\begin{abstract}
Pressure on everyone is there, the effects of different pressure are not same. Pressure to a certain extent will affect people's physical and mental health. In general, the people in the workplace stress are generally bigger. With the development of the society, everyone has different degree of pressure feeling from different aspects. Teachers is a special profession, there are many unstable factors are facing some special groups. As the new head teachers, it is more stressful. Each shape of the teacher in charge start from "newbie", for the new head teacher, they don't have a clue about work, large workload, class, etc., it should not be very easy to generate a lot of pressure. According to the authority scale among a number of teachers in primary schools, analysis the new head teachers' work stress situation and find a reasonable solution.
\end{abstract}

\section{Introduction}

Over recent years, the massive influx of rural population city, left-behind children has become a common phenomenon. Many scholars have put forward their views from different angles, such as studies of left-behind children psychology, studies the present situation of left-behind children, research on the problem of left-behind children exist, and the exploration of relevant countermeasures. Their growth environment, living habits and psychological conditions cause many social problems, not just our concern, are also eyeing this group in society [1].

\section{Current Situation on Left Behind Children in Rural}

Many left behind children with single monitoring and generation of insulation monitoring is given priority to, their way of education itself, is not suitable for children also seldom focus on the development of children's mental health, especially its regional background won't be able to make children happy learning [2, 3].

(1) The parent-child communication between left-behind children. The current social development, but will still have a lot of places can't change soon, especially some extremely poor areas, their parents go out to work. , according to a new report from CCTV news 180 million rural migrant workers in our country, and a total of 675 million, China's rural population accounted for $26.7 \%$, so to speak. Is mostly young adults, they are in the junior, after holding to give them a comfortable mood, set foot on the way go out to work. The more people and migrant workers, the more rural left behind children. Some of them want to take their children to work, but even brought when I was a child, the child also don't have time to take care of them and to their big think to a nearby school, and by the expensive and sponsorship money to give back to the in situ, every day to work to earn money to pay my town, also makes the parents after considering the child back to grandparents, also conveniently near your home to school. So that no more than 18 years old of children is called left-behind children, their long time spent in the countryside, with most left behind experience, have a plenty of to near relatives and neighbors, some of them are living with my grandparents. But no parents only grandparents in a family is not a complete family, parents will be keen to children, which others cannot give. Others, after all, not parents, also can not be like their parents to teach children, both psychology and education aspects of left-behind children are ignored. 
(2) The left behind children mostly unhealthy psychological. Not only the left-behind children, is a normal family, once the child feel left out, such as home and had two children, older children psychology will produce jealousy, think parents only love yourself. Left-behind children for a long time can't get the attention of parents, and parents had no emotional communication, initially can produce depressive mood, some children in the long run will produce the irascible ideas such as split personality. After the test, this is a sign of lack of parent-child education, children can't get attention in this regard, will try to draw the attention of parents, but parents of left-behind children in working, they will only in the telephone, ask the result quality ever listen to your teacher, this is not the result of children want, their ideas will be because of these reasons, more and more extreme. And this kind of idea not only harm the child's psychological problem is harm to the physical development of children, a long-term psychological problems of children body also will be more and more depressed.

(3) Poor quality of life the remaining area. As is known to all, left-behind areas both in education and environment construction is very backward, young teachers don't want to to stay to teach, on the one hand, because there have no big development, on the one hand, where his home is not stay too. Some also to reform local government related regions, dole out money, but also is better than nothing. In left-behind areas when teachers are mostly degree is not high, a lot of places the highest degree in high school, however, they are just graduation soon near his hometown, can't continue to go to school, the choice of the teaching. They are teachers, education quality is better than natural city urban teachers are required also often do related training. So the rural teachers wouldn't notice the left-behind children education is not appropriate, and the elders are also a native of farmers, more won't know once missing related aspects of the education, children will eventually hung out in school, don't study hard.

(4) Security of left behind children cannot guarantee. Deficiency of the backward areas, teachers, relatives of minor correction, makes the safety of left behind children has become a big hidden trouble. Often listen to the news in the minor teenage pregnancy and hospital abortion also can see the most is a minor, also some until soon gave birth to the child be infringement, but the infringe object is the uncle at home. Although education in China has been very implicative, but neglect is the most direct factors of parents and other relatives, parents, even more than on the phone with your child and talk more also won't make things become more and more serious. All say children is a blank sheet, how do you draw what they become, the child is no consciousness, so you need to adults, this is a necessary responsibility as parents, so children can when being bitter.

\section{Cause of Problems on Left Behind Children in Rural}

Left-behind children increase day by day, people often study the causes. Have a family, school and social aspects, the author also many related aspects of information collection, it is concluded that the following points $[4,5]$ :

(1) Parents' backward education idea. Different families have different concepts of education, as a senior intellectual family and related to teachers' professional family, their degree is high, naturally know how to education of children, and give priority to with children, consider their ideas. But rural left-behind family is different, they are working outside the contact way of children under education, parents education just carry on own way, there are a lot of family the children are more discipline, grandparents for every generation of children is to give love, they should have for their children's love for his grandchildren, they also take it for granted that education of grandchildren, but some of the left-behind children learned the grandparents' diligence and integrity, others due to excessive spoiling children become stubborn. Even if the parents will come back once or twice during working outside, children have also been used to listen to your ancestors, ignore the discipline of parents, even what parents like to use violence.

(2) Lack of family education. Children are expected to parents concern, according to Pygmalion Effect, the higher the expectations for children, parents to the child's motivation. But the expectations of parents of left-behind children was negative for them, they to the child's request is too high, but does not carry on the study guide, children will not get into the habit of consciously to 
learn. Parent-child communication is affection cannot replace other, after all, the generation gap between parents and children don't gap is too big, and will have a great generation gap between grandparents and relatives, also can saying is the child itself some attachment to their parents. Parents are selfish and think just manages their food and clothing live line, to the other disciplines is also no problem, if the children falling grades will teacher didn't teach good, is not to think you don't have good education, grandparents too spoiled. And there are some single-parent children, lack of a father or a mother's love, missing psychological produce a variety of diseases. This is all bad results of family education.

(3) The abandon of left-behind children. Itself also has a desire for the parents and children, listen to their parents to learn knowledge, more and more busy, but as parents telephone less and less, regardless of in the home, the school can't deep tube, children lost could have achievement self-confidence, become desperate, even think that parents will be noticed after abandon oneself, so the street a lot more hooligans, that most of them are left behind children. Also often see in the news, some school students jump off a building events, things happen later, parents will only hold corpse cry, never thought I was doing something wrong.

(4) Social form cause too many left behind children. According to the situation of left-behind children, the government has done relevant decisions, but these decisions do not correspond to the children. Compared to the rural and urban education, after all, it is not fair. Fast urban development, the salary is high, the teachers are willing to go to, the people who work for others is also more and more, also makes more and more left behind children. Rural government subsidies, but make up only a small number of people are not willing to the countryside, don't want to get her youth to the countryside, many government decisions cannot be implemented, gives facilities also slowly become waste, policy failure in the end.

\section{Educational Countermeasures on Left Behind Children in Rural}

Read so many books, heard so many news, when I hear the problems of the left-behind children feel must contribute, although they like the grass, but they are still very stubborn stand, waiting to be somebody one day, waiting for one day to be rescued, the author also research related countermeasures to solve these problems [6-8].

(1) Concerned with left-behind children empathy. Is not to say go to see the psychological doctor is suffering from mental illness, in a foreign country, a lot of people think the psychological doctor can well solve your troubles, and timely and convince yourself. Found that children have a bad mood, so it is timely attention to, how to communicate with them, to open their heart, so you can understand what they really need. Youth is the child's rebellious period, students often impulsive, they have no place to vent pressure, parents also ignore themselves and step can only fight or just learn not to go home. So they really want to know what is the most important.

(2) The relevant aspects of guidance to their parents. Parents can go out to work, but also want to call home, more concerned about their children's daily life, let know that parents love their children, working outside also can think of them. As far as possible during the working time to go home to visit the child, and in a timely manner to ask the teacher in charge and the school, the school teachers to communicate more with their parents, the proper way to teach their children education, tell them how to do ability to make their children more confident, more encouraging them not a negative. The idea of parents to change the sticks out under a son, age has different, children have different ideas and they will be willing to communicate with parents, tell their parents what they want. Has to strictly control the material, can't hold more allowance compensation psychology, lavish in their bad habit, it is not compensated for the child's way. Let them learn to be grateful. After all, it all came easily.

(3) Schools and teachers to strengthen students' attention. Don't have my parents once, the school and teacher's responsibility is very big, they want to protect children during the period of school safety, should be timely attention to the students' psychological if there was any bad feelings, and communicate in a timely manner. Although there are more and more left-behind children, but we can't abandon any one. Try to set up some more suitable for children's extracurricular activities, 
promote peer exchanges, let them in a pleasant environment, there will be a good state of mind. Also want to strive for the classroom is no longer boring, let students can put all the thoughts to parents, give some attention left-behind children, they are also the future of our motherland.

(4) The social from all walks of life. Walked into the campus often see for poverty-stricken areas to donate money, clothes, etc. Many will voluntarily contribute an own love, although not much, but also represent an own heart. Often hear such and such stars do hope primary school, even to teach themselves. This is not a show, this is the social kindness. It's mostly for the sake of national construction, farmers working in donations for children but also for the country, although this force is not big enough, but always a productive to keep working on it. The author will also contribute their love, more than one part.

\section{Conclusion}

The emergence of left behind children is not their voluntary, and is the special phenomenon in a special period, they are hard to live his life, seldom realize complete family of love. Schools might give hands to them and the governments often study related countermeasures, for as the primary problem to solve the problem of left-behind children. Now, of course, countries do this problem as the first problem to solve, we can't just focus on, also want to study more relevant countermeasures. So the author in this society a little more love, a little more attention, let they can fly under the blue sky.

\section{Acknowledgement}

This work is supported by Teaching reform project of Bohai university in 2015: Research on evaluation index system construction and action for process teaching of flipped classroom (BDJG-15-YB-B-012); Postgraduate teaching reform project of Bohai university in 2015: Action research on "ability to advanced" under the primary school education professional master talent training mode reform; Research project of undergraduate teaching reform of higher education in Liaoning Province in 2014: Action research on primary school education professional talent training mode reform based on standard.

\section{References}

[1] X. L. Yan, P. Yang, "Family education new discuss," Beijing University Press, 2012.

[2] X. D. Jin, A. Z. Yu, "To explore the children's grandparents family education problems of Korean left behind: Taking Yanji city of Jilin Province as an example," Modern Educational Science, no. 2, 2010.

[3] Z. Y. Li, Y. Liu, "A study on the misunderstanding and countermeasures of "left behind children" education," Modern primary and secondary education, no. 6, 2007.

[4] Z. H. Zhou, "The influence of family education on the rural left behind children and the Countermeasures," Jiangxi Social Sciences, no. 11, 2003.

[5] C. R. Duan, K. Yang, "Research on the situation of left behind children in rural areas of China," Population studies, no. 5, 2008.

[6] S. Tan, "A review on the study of left behind children in rural China," Chinese Social Sciences, no. 1, 2011.

[7] F. L. Zhou, C. R. Duan, "Review of research on left behind children," Population journal, no. 3, 2006.

[8] K. Hu, "A survey on the social support of the left behind children in rural areas," Chinese Journal of health psychology, no. 8, 2011. 